\title{
Historiografia do patrimônio na década de 1980? Algumas considerações
}

Historiographical approaches to heritage in the 1980s? Some considerations

https://doi.org/10.1590/1982-02672020v28d2e52

\section{LUCIANO DOS SANTOS TEIXEIRA'}

https://orcid.org/0000-0002-4433-557X

Instituto do Patrimônio Histórico e Artístico Nacional / Rio de Janeiro, RJ, Brasil

RESUMO: Este artigo analisa a constituição de uma abordagem historiográfica sobre o patrimônio cultural no Brasil, a partir de duas obras de referência para o estudo do tema, editadas na década de 1980: Produzindo o passado, organizada por Antonio Augusto Arantes (1984), e Proteção e revitalização do patrimônio cultural no Brasil: uma trajetória (1980), lançada pelo Secretaria do Patrimônio Histórico e Artístico Nacional (Sphan/Pró-Memória). Enfatizando tanto o contexto em que essas obras foram publicadas, como as características que as tornaram representativas da nova abordagem do patrimônio cultural, o texto ressalta, para além das novas temáticas propostas por esses títulos, novas perspectivas, que traduziam, por sua vez, novos olhares sobre a cultura, a memória e o passado materializado da nação. Abordagens partir daí foi possível organizar novo discurso patrimonial, associado a noções como de bem cultural, e, com isso, surgiu a possibilidade da escrita da história do patrimônio no Brasil.

PALAVRAS-CHAVE: Patrimônio Cultural. Historiografia. Escrita da História.

ABSTRACT: This article analyzes the constitution of a historiographical approach on cultural heritage in Brazil, based on two works considered as references for the study of the theme, published in the 1980s: Producing the past, organized by Antonio Augusto Arantes (1984) and

\begin{abstract}
1. Doutorando em História pela Universidade Federal Fluminense, com mestrado em História Social da Cultura pela PUC-Rio e graduação em História pela Universidade do Estado do Rio de Janeiro. Desde 2006, é servidor do Instituto do Patrimônio Histórico e Artístico Nacional (Iphan), onde atualmente é professor do mestrado profissional em patrimônio cultural, lecionando a disciplina Instrumentos de Valoração e Identificação do Patrimônio. E-mail: <luchis91@yahoo.com.br>.
\end{abstract}


Protection and revitalization of cultural heritage in Brazil: a trajectory (1980), launched by SPHAN / Pró-Memória. Emphasizing both the context in which these publications were launched, as well as the internal characteristics that made them representative of a new approach to cultural heritage, it highlights, in addition to the new themes proposed by these works, new approaches, which in turn translated new looks at the nation's culture, memory and materialized past. Such approaches organized a new patrimonial discourse, associated with notions as a cultural asset, and at the same time demarcated the conditions for the possibility of writing the history of heritage in Brazil.

KEYWORDS: Cultural Heritage. Historiography. Writing History. 
Definir o que seja bem cultural implica por princípio numa antidefinição, dado a multiplicidade das manifestações que emergem das estruturas sociais formadoras da civilização brasileira. ${ }^{2}$

parágrafo de abertura do editorial do número zero do Boletim Sphan/ Pró-Memória, assinado por Aloísio Magalhães, chama atenção para a centralidade de uma noção até então pouco associada à temática do patrimônio, o bem cultural. Como veremos, esse texto busca explicitar as novas implicações que os termos "cultura" e "patrimônio" passaram a ter com a proposta de Aloísio, no contexto de fundação da Secretaria do Patrimônio Histórico e Artístico Nacional/Fundação Nacional Pró-Memória (Sphan/Pró-Memória). Porém, para além dessa instituição, a epígrafe de nosso artigo traz à tona outra questão, menos óbvia, mas igualmente relevante para entender as transformações que ocorriam no campo do patrimônio brasileiro naquele período.

A referência às "manifestações que emergem das estruturas sociais formadoras da civilização brasileira", responsáveis pela "antidefinição" da noção de "bem cultural", ou seja, pelo reconhecimento da impossibilidade do termo de dar conta de uma realidade social multifacetada, aponta para perspectiva empirista que entende a cultura como composta pela diversidade de elementos concretos - as "manifestações" - que impõem limites à sua acepção em termos gerais e abstratos.

Esse olhar atento às particularidades dos "bens culturais" e das "referências", como concebidas pelo Centro Nacional de Referência Cultural (CNRC), ${ }^{3}$ é visto como ponto de partida para compreender a "civilização brasileira" e sugere nova abordagem ao patrimônio cultural, sinalizando as mudanças que a área do patrimônio cultural vinha sofrendo e, ao mesmo tempo, indicando projeto transformador para sua preservação, então em consolidação.

A realidade empírica, em sua dinamicidade e complexidade, passaria a exigir do Estado brasileiro sua "adequação" às "solicitações do nosso tempo". ${ }^{4}$ Evidentemente, Aloísio Magalhães acenava para a fusão institucional entre o CNRC, o Programa de Cidades Históricas (PCH) e o Instituto do Patrimônio Histórico e Artístico Nacional (lphan), e que iria dar origem à Sphan/PróMemória. Mas indicava também, de maneira mais ampla, uma inversão nas formas como se pretendia lidar com as "estruturas sociais formadoras da civilização brasileira". Ao Estado brasileiro caberia não mais o papel de instituinte da identidade nacional, fixando signos e estabilizando sentidos e representações do Brasil, sua origem e futuro imaginado, dentro de uma matriz interpretativa que enfatizava a unidade cultural, correlata da territorial, como promovido pelo antigo Serviço do Patrimônio Histórico e Artístico Nacional (Sphan), sobretudo nas décadas de 1930 e 1940.5 Sua função seria agora, principalmente, a de
2. SPHAN/Pró-Memória (1979, n ${ }^{\circ}$ 0, p. 1).

3. Para uma boa discussão sobre o legado do CNRC, $\mathrm{cf}$. Dutra (2017)

4. Ibidem. p. 2 .

5. Para um panorama das primeiras décadas da história da preservação do patrimônio cultural no país, existe uma sólida bibliografia, na qual se destacam os trabalhos de Chuva (2009), Velozo (1996), Rubino (1996) e Fonseca (2005). 
6. Meneses (2012, p. 33). Meneses foi um autor/ator decisivo nesse processo de transformação ocorrido no campo do patrimônio, nas décadas de 1970 e 1980.

7. "A Constituição Federal de 1988, ao conceituar o patrimônio cultural brasileiro, armou uma bomba relógio que está longe de ser desativada" (Meneses, 2017, p. 39). incorporar os diversos grupos sociais formadores da sociedade brasileira, reconhecendo e legitimando suas múltiplas expressões, valorizando-as e atuando como instância mediadora da sua inescapável diversidade cultural.

Estava em jogo o "deslocamento da matriz" que Ulpiano Bezerra de Meneses ${ }^{6}$ via na Constituição de 1988, transferindo do Estado para sociedade o poder de definir o que é patrimônio cultural, e que teria, a seu ver, o efeito de uma "bomba-relógio prestes a explodir", 7 por seu potencial transformador nas políticas públicas brasileiras. Esse fenômeno pode ser visto, na perspectiva das mudanças que estamos analisando aqui, como ponto de chegada, a conclusão de um percurso, cuja nascente data do início da redemocratização e cujos contornos se tornaram cada vez mais nítidos ao longo da década de 1980.

Esse deslocamento permitiu ainda que o patrimônio cultural, como campo de disputas políticas e intelectuais, pudesse ser visto não mais como esfera neutra, repositório de bens, vestígios e lugares, representativos da memória e da identidade de uma nação, mas como construção social e historicamente determinada. Não seria exagero afirmar que os anos 1980 inauguraram uma abordagem historiográfica do patrimônio no Brasil ou, dito de outro modo, a possibilidade de uma escrita da História do patrimônio no Brasil.

Tratava-se de um tipo de abordagem disseminada em artigos, capítulos e outros textos esparsamente divulgados, mas que ainda não estavam reunidos em livros ou obras de maior fôlego. Não por acaso, há escassos registros da participação de historiadores de ofício nessa primeira produção. Pode-se dizer, na perspectiva de uma historiografia do patrimônio, que a construção dessa abordagem se deu por contribuições de múltiplas disciplinas, em que o conhecimento histórico aparece apropriado e mediatizado pelos saberes dessas áreas.

Nesse sentido, exploraremos a seguir duas obras que contribuíram para esse percurso, e que estabeleceram uma clivagem entre passado e presente, entre concepções de patrimônio e práticas de preservação que se pretendiam novas, em oposição a concepções, valores e procedimentos considerados antigos, identificados genericamente com o período de implantação das políticas de proteção do patrimônio no país, tendo a criação do Serviço do Patrimônio Histórico e Artístico Nacional (Sphan), em 1937, como marco referencial: Produzindo o passado, do professor Antonio Augusto Arantes, lançado pela editora Brasilense em 1984, e o livro Proteção e revitalização do patrimônio cultural no Brasil: uma trajetória, publicado pela Secretaria do Patrimônio Histórico e Artístico Nacional/Fundação Nacional Pró-Memória (Sphan/Pró-Memória), em 1980. Esses dois livros tiveram, entre outros, o objetivo explícito de se colocarem no centro do debate sobre o lugar do discurso patrimonial nas disputas intelectuais e políticas que se intensificaram no período da 
redemocratização, entre o final da década de 1970 e início dos anos 1980. Ao mesmo tempo, identificavam claramente suas procedências institucionais, que demarcavam seus respectivos lugares de origem, determinando na mesma medida as tradições com as quais dialogavam e as direções distintas que almejavam seguir.

Duas obras, de caráter, intenção e fôlego muito distintos, mas cada uma, a sua maneira, fundamentais naquele momento para se estabelecer alguns marcos conceituais significativos, e que ainda hoje têm sua importância nos debates sobre o assunto. Além disso, na perspectiva adotada aqui, colocaram o tema do patrimônio cultural como objeto histórico, resultado de uma construção social e intelectual, detentora de recorte espacial e temporal específico.

Esses textos contribuíram para moldar interpretações e narrativas que foram sendo construídas nas décadas seguintes a respeito do patrimônio cultural, do papel do Iphan e dos intelectuais que ajudaram a criar uma política de preservação no Brasil, aspectos que podem ser resumidos de forma geral na divisão da história do Iphan (e, por extensão, do patrimônio no Brasil) em fases "personalizadas"; no afastamento dessa política em relação aos marcos mais amplos das políticas estatais no Brasil; e na eleição de marcos conceituais definidores de cada fase "proteção/patrimônio histórico e artístico", "revitalização/bem cultural".

Ambas concorreram para o desenvolvimento daquilo que Laurajane Smith nomeou como "discurso autorizado de patrimônio", ${ }^{8}$ entendido nesse ponto como "discurso profissional que privilegia valores e conhecimentos de especialistas sobre o passado e suas manifestações materiais e domina e regula as práticas de patrimônio profissional". 9

\section{PROTEÇÃO E REVITALIZAÇÃO DO PATRIMÔNIO CULTURAL NO BRASIL: UMA TRAJETÓRIA}

Nosso primeiro objeto de análise é a obra publicada pelo Sphan/PróMemória em 1980, na série Publicações do Sphan, sob o número $31 .{ }^{10}$ No livro de 143 páginas, 22 são dedicadas a uma apresentação histórica, nove a elementos pré-textuais, 112 páginas a anexos (legislações, transcrições de trechos de documentos históricos e entrevistas então recentes) e uma última página de bibliografia, na qual estão arrolados apenas oito títulos.

A obra se apresenta como um documento ${ }^{11}$ com a seguinte estrutura: Antecedentes; Sphan - o início da proteção; PCH: novos recursos, revitalização de conjuntos e integração comunitária; CNRC: a dinâmica cultural; Sphan/Pró-
8. A autora assim o define, de maneira geral: "um discurso ocidental dominante sobre patrimônio, que chamo de 'discurso autorizado do patrimônio', que trabalha para naturalizar uma série de suposições sobre a natureza e o significado do patrimônio. Embora esse discurso esteja inevitavelmente mudando e se desenvolvendo, e varie em diferentes contextos culturais $\mathrm{e}$ ao longo do tempo, há, no entanto, um foco e ênfase específicos - principalmente a atenção que ele dá às "coisas". Esse discurso muitas vezes auto-referencial se baseia e naturaliza simultaneamente certas narrativas e experiências culturais e sociais - geralmente ligadas a ideias de nação e nacionalidade. Inserida nesse discurso, há uma série de pressupostos sobre os valores culturais inatos e imutáveis do patrimônio que estão ligados e definidos pelos conceitos de monumentalidade e estética" (Smith 2006, p. 4) tradução nossa

9. Ibidem (2006, p. 4).

10. A série Publicações do $S P H A N$ teve grande importância na política de comunicação estabelecida pela instituição federal de preservação, desde sua fundação em 1937. Criada e coordenada por Rodrigo Melo Franco de Andrade, era encarada como não apenas como uma forma de divulgação do SPHAN, mas também de estudos e documentos que complementassem as ações institucionais. Juntamente com a Revista do SPHAN (criada no mesmo ano), teve papel decisivo na formação e consolidação das políticas de preservação do patrimônio no Brasil. Durou, pelo menos, até década de 1980. Para uma breve análise da série e da Revista em suas trajetórias cf. Leal et al. (2012). Para uma análise específica $\mathrm{e}$ 
mais aprofundada da Revista, cf. Silva (2010).

11. Destaco aqui o caráter formal-burocrático do termo documento, como ele próprio se apresenta, mas que pode apontar para novos sentidos que o termo foi adquirindo ao longo da década de 1980 e que ainda necessitam um estudo mais aprofundado. Cf. Nascimento (2016).
Memória: a fusão; anexos; bibliografia. Da apresentação histórica, três páginas tratam dos chamados "antecedentes", ou seja, o período anterior à criação do Sphan (Capítulo 1), e nove são dedicadas à história do Sphan (Capítulo 2): em duas fases, a primeira, de Rodrigo de Melo Franco de Andrade, e a segunda, de Renato Soeiro, antecedidas de uma síntese dos esforços da criação de uma instituição governamental de preservação do patrimônio no país.

O Capítulo 3 tem apenas duas páginas e conta a história da criação e fim do PCH. O quarto capítulo tem três páginas e narra a breve trajetória do CNRC. O quinto e último capítulo fala sobre a criação da Sphan/Pró-Memória, com a fusão do Iphan, CNRC e PCH, sendo, portanto, uma síntese dos capítulos anteriores. Em seguida, vêm os anexos, dos quais destaco, além da transcrição da legislação pioneira de proteção do patrimônio no Brasil, o último anexo (de número XXX), uma entrevista do então assessor da direção geral da Sphan, Irapoan Cavalcanti de Lyra, na qual são explicitados não apenas questões de ordem geral sobre a recém-criado Sphan/Pró-Memória, mas também problemas de ordem operacional que justificariam o processo de engenharia político-administrativa que levou à criação daquele órgão com estrutura administrativa incomum.

Com a fundação no governo federal em 1979 da Sphan/Pró-Memória, constituída em torno da figura de Aloísio Magalhães e materializada no livro Proteção e revitalização do patrimônio cultural no Brasil: uma trajetória, e com o convite ao antropólogo Antonio Augusto Arantes para assumir o Conselho de Defesa do Patrimônio Histórico, Arqueológico, Artístico e Turístico (Condephaat), órgão de preservação do patrimônio do governo estadual de São Paulo, em 1982, nossa hipótese aqui é de que esse trabalho de reorganização institucional possibilitou a gênese de algumas matrizes de ação e pensamento que marcariam a produção intelectual sobre o assunto na década de 1980 - não apenas na construção e consolidação de certas narrativas sobre a história do patrimônio brasileiro, mas também na interpretação de aspectos da nossa cultura, com ênfase em novas concepções de patrimônio que circulavam nos meios acadêmicos naquele momento e, sobretudo, na projeção identitária de um país que se desejava construir.

Evidentemente, esse processo não pode ser descolado do quadro mais amplo das discussões e propostas que já buscavam atrelar cultura e desenvolvimento naquele momento, como as propostas educacionais e culturais que vinham sendo debatidas e defendidas no governo Geisel, durante a gestão de Ney Braga à frente do Ministério da Educação e Cultura (MEC). Vale mencionar, por exemplo, o surgimento da expressão "bens culturais" no Plano de Ação Cultural, formulado naquele contexto: 
Em agosto de 1974, o Ministro Ney Braga, proferiu palestra na Escola Superior de Guerra, sobre a política educacional e cultural do Brasil. Ao tratar da cultura, ele apresentou um projeto de reformulação do Plano de Ação Cultural, executado no ano anterior, afirmando que a política cultural do Ministério estaria centrada em diretrizes bem estruturadas que giravam em torno de três atitudes fundamentais: a) difusão das manifestações do âmbito da cultura; b) incentivo à criatividade artística brasileira; e, c) preservação e defesa dos bens culturais. ${ }^{12}$

É possível notar que a formulação de novos olhares sobre a noção de cultura e de sua operacionalização como políitica pública teve impacto direto nas concepções de patrimônio em disputa, assim como no esforço de incorporação de agentes sociais emergentes que seriam cada vez mais visíveis na vida política brasileira no período da redemocratização.

A obra Proteção e revitalização do patrimônio cultural no Brasil: uma trajetória é descrita por Márcia Chuva como "[...] a primeira versão oficial sobre a história da preservação do patrimônio cultural no Brasil". ${ }^{13}$ Nesse sentido, como aponta a autora, oferece $\mathrm{o}$ esboço de uma periodização que vai consagrar, dali por diante, as expressões "fase heroica" e "fase moderna", para descrever, respectivamente, as gestões de Rodrigo Melo Franco de Andrade e Aloísio Magalhães à frente do Iphan. ${ }^{14}$

De maneira geral, podemos enumerar cinco matrizes que resumem as transformações ocorridas nesse âmbito, em meio à multiplicidade de propostas, discussões e definições que se ensaiavam no período. Cada uma delas aparece de maneira mais ou menos explícita no livro, e as descrevemos mais detalhadamente a seguir:

1) a ideia de bem cultural - talvez a mais importante inovação no campo do patrimônio, desde sua institucionalização nos anos 1930 e 40;

2) economia do patrimônio - a ideia de uma economia da cultura associada ao patrimônio, relacionada ao urbano, ao turismo e à economia popular;

3) nova pedagogia do patrimônio: a reelaboração de um projeto educacional, reativando e ressignificando o sentido missionário da atuação na área;

4) a ideia de patrimônio como trabalho: sua compreensão como trabalho e, por extensão, da cultura como atividade produtiva, não mais como atividade do espírito, fruto do cultivo de uma elite letrada;

5) o patrimônio como expressão de criatividade e vitalidade das comunidades que formam o povo brasileiro, não somente como materialização de sua identidade e memória, mas como grupos que precisam ser envolvidos na ação de preservação.
12. Calabre (2008, p. 7) grifo nosso.

13. Chuva (2012b, p. 147).

14. Ibidem, (p. 148). De 1937 a 1967, a gestão de Rodrigo Melo Franco de Andrade no Sphan, assim denominado até 1946 , quando se torna Diretoria de Patrimônio Histórico e Artístico Nacional (DPHAN). De 1979 a 1982, a gestão de Aloisio Magalhães na SPHAN/Pró-Memória. 
15. Magalhães (1985, p. 63).

16. SPHAN/Pró-Memória (1979, p. 26).

17. Uma boa síntese das discussões sobre esse tema é apresentada em Guedes (2016).

18. Fonseca (2000, p. 13).

19. O CNRC foi criado em 1975 , a partir de um grupo de políticos e intelectuais ligados ao Estado brasileiro, que pretendia inicialmente "criar um banco de dados sobre a cultura brasileira, um centro de documentação que utilizasse as formas modernas de referenciamento e possibilitasse a identificação e o acesso aos produtos culturais brasileiros". No relatório técnico $\mathrm{n}^{\circ}$ 1 , de $2 / 7 / 1975$, o objetivo do CNRC era definido como o 'traçado de um sistema referencial básico para a descrição e análise da dinâmica cultural brasileira'" (Fonseca, 2000, p. 163). Vale destacar que não havia no CNRC preocupação direta com a temática do patrimônio. Seu intuito era muito mais de relacionar a "dinâmica cultural brasileira" com o "desenvolvimento econômico".

20. Leal (2009).

\section{Bem cultural}

O surgimento da ideia de bem cultural pode ser encarada não apenas como porta de acesso a uma compreensão ampliada do patrimônio, mas, como definido por Aloísio Magalhães, pode ser identificada como a própria noção de patrimônio:

[o] conceito de bem cultural extrapola a dimensão elitista, de "o belo e o velho", e entra numa faixa mais importante da compreensão como manifestação geral de uma cultura. $\bigcirc$ gesto, o hábito, a maneira de ser da nossa comunidade se constituem no nosso patrimônio cultural. ${ }^{15}$

Ou ainda segundo outra definição, presente no livro em questão, de que - "bem cultural é importante catalisador das transformações", 16 indicando o potencial que essa noção assumia como foco da proteção do patrimônio no país. A ideia de bem cultural, como se desenvolveu no Brasil, a partir de seu uso pela Organização das Nações Unidas para a Educação, a Ciência e a Cultura (Unesco) na Convenção de Paris de 1970, relativa às medidas para proibir e impedir a importação, exportação e transferência de propriedades ilícitas dos bens culturais, ${ }^{17}$ ainda carece de investigações mais aprofundadas, mas sua associação com as discussões sobre o patrimônio cultural tornou-se cada vez mais evidente nos textos produzidos naquele período.

Cabe destacar que o próprio termo "patrimônio cultural" - que, por sinal, também merece investigação de sua origem e disseminação no Brasil e no mundo - aparece, no mesmo contexto histórico, como nova definição, que substituirá gradualmente a antiga expressão "patrimônio histórico e artístico". Cecília Londres, em formulação que se tornou célebre, ${ }^{18}$ destaca o papel do Centro Nacional de Referência Cultural (CNRC) ${ }^{19}$ como órgão responsável por constituir uma "concepção antropológica de cultura", que teria impacto decisivo em novos sentidos de patrimônio que estavam sendo então gestados.

\section{Economia do patrimônio}

Em consonância com o uso da expressão "bem cultural", surgiu o que se pode chamar de economia do patrimônio, que aparece tanto na atuação do CNRC, quanto na preocupação, intensificada na década de 1960, do Estado brasileiro com os impactos do desenvolvimento econômico e do turismo. ${ }^{20}$ Nesse sentido, a atuação da 
Sphan/Pró-Memória foi constituída, pelo menos no início, em função tanto da valorização das expressões e manifestações populares quanto da criação de meios de sustentação de seus portadores. Essa atuação conferiu ao novo órgão a tarefa urgente de salvação nacional, diante dos desafios e das ameaças dos meios de comunicação de massa e da consequente tendência à homogeneização da cultura mundial, vistos como principais riscos para a existência de uma cultura brasileira autônoma e rica. ${ }^{21}$

O Boletim Sphan/Pró-Memória, criado em 1979, é importante fonte documental para o estudo das múltiplas ações e discussão dos impactos sociais e econômicos da preservação do patrimônio, em particular do patrimônio urbano. Um dos eventos mais discutidos nos primeiros boletins foi o Seminário de Ouro Preto, realizado em 1979. Nesse seminário ${ }^{22}$ - ocorrido por ocasião de intensas chuvas que provocaram a destruição de parte da cidade, afetando inclusive o centro histórico -, o que se debateu principalmente não foram somente as circunstâncias externas que afetavam e eram afetadas pelas políticas de patrimônio, mas igualmente os usos que a sociedade fazia de seus bens patrimoniais, o que punha em evidência as questões centrais do para quê e para quem preservar, para além dos debates habituais sobre os critérios de seleção e de valoração de o quê preservar. ${ }^{23}$

Essa situação ilustrava bem o tipo de preocupação dos gestores e formuladores de políticas públicas, assim como a intelectualidade dedicada ao patrimônio cultural, que muitas vezes era chamada tanto para intervir nas discussões quanto para atuar nos órgãos de preservação. Como seria possível incorporar as demandas e exigências de uma população que até então era largamente negligenciada - não apenas na questão do patrimônio, mas nas políticas públicas em geral - dentro das estruturas burocráticas do Estado, ainda gradualmente saindo de seu período mais autoritário? Esse despertar paulatino para o reconhecimento de que o cidadão, afinal, deveria ser, senão o centro das políiticas de preservação, ao menos parte integrante delas, e transparecer na ideia de que os bens culturais eram produzidos e circulavam dentro de um processo socioeconômico, movidos por sujeitos e agentes que conferiam características peculiares a esses bens.

\section{O patrimônio como missão educativa}

A epígrafe de Mário de Andrade, no livro Proteção e revitalização do patrimônio histórico e artístico nacional, afirma: "defender o nosso patrimônio histórico e artístico nacional é alfabetização". Ou seja, essa ideia traduz a aspiração missionária do patrimônio cultural, ao mesmo tempo reconectando a
21. Gonçalves (2002).

22. Iphan (Boletim 03, 1979 , p. $1-4)$.

23. Como disse na época Luizí Felippe Perret Serpa, coordenador de projeto do CNRC, "o que aconteceu [...] é que se desenvolveu toda uma ideologia nacional sobre Ouro Preto, mas não se desenvolveu o diálogo. Não se trata de negar o direito de todos falarem sobre Ouro Preto, mas de reconhecer o direito da população de definir seu destino" (Sphan/Pró- Memória, 03, 1979, p. 4). 
24. Para uma análise crítica desse recurso legitimador da figura de Mário de Andrade nas políticas de patrimônio no Brasil, e de como isso serviu a embates internos na definição dos novos rumos das políticas de preservação, cf. Chuva (2012b). "nova política patrimonial" que se pretendia defender e divulgando as práticas e tradições já estabelecidas na área no Brasil.

Esse artifício retórico coloca em primeiro plano dois aspectos fundamentais que marcariam, dali por diante, a política federal de preservação do patrimônio no país, moldando ao mesmo tempo a maior parte das discussões e interpretações que se dariam ao longo de toda a década: o recurso ao nome de Mário de Andrade como instância de consagração e legitimação ${ }^{24}$ e a retomada de um sentido missionário da educação por parte do governo brasileiro, marcante no período do Estado Novo (1937-1945), e que seria reativado, em novos moldes, pelo governo militar por meio de um novo projeto pedagógico federal. Mediante uma nova concepção de cultura, que pretendia incluir os novos agentes sociais que surgiam no período de abertura política, marcadamente as camadas populares, o patrimônio tornava-se um catalisador das aspirações e demandas sociais. Evidentemente, as políticas de preservação do patrimônio compunham um rol mais amplo de ações nesse sentido, mobilizadas principalmente pelo Ministério de Educação e Cultura (MEC).

Contudo, é possível perceber outra dimensão nessa citação, menos evidente que as anteriores, e que parece incidir na nova política institucional que o projeto da Sphan/Pró-Memória pretendia inaugurar: uma concepção educacional que entendia a população brasileira como ignorante de sua própria cultura; a quem, portanto, era necessário ensinar o que era o patrimônio, oferecendo as letras às quais somente o conhecimento especializado possuía acesso. Nesse sentido, sugerimos como hipótese de trabalho a ser ainda aprofundada, que o patrimônio em sua dimensão educativa, malgrado a proposta de inclusão dos grupos sociais que passava pouco a pouco a permear o discurso patrimonial, concebia um tipo de relação entre Estado e sociedade que marcava a diferença entre essas esferas e as hierarquizava. Sendo a ideia de patrimônio por si só inquestionável, caberia ao governo brasileiro oferecer à população os rudimentos do que integraria esse Patrimônio (com "P" maiúsculo), alfabetizá-la para a adequada compreensão do seu valor.

\section{O patrimônio como trabalho}

Todavia, qualquer concepção educacional associada ao patrimônio pressupunha reconhecê-lo não mais como dimensão à parte da sociedade, mas como aspecto vital dela. Dessa maneira, a compreensão do patrimônio também como trabalho transformou a ideia de cultura, passando de uma acepção anterior, associada à ideia de cultivo do espírito, difundido entre as camadas mais "cultas" 
da sociedade e disputada pelos intelectuais que a defendiam - um repertório artístico e memorialístico selecionado por e para eleitos -, para um novo significado, "antropológico", em que a cultura é vista como produto da dinâmica social, fruto do trabalho social e com a qual caberia mais diálogo do que cultivo.

Como expressão de novas condições de atuação profissional que, por sua vez, refletiam transformações mais profundas nas relações de trabalho que ocorriam no país, o técnico, o especialista e o estudioso passam também a ser vistos como trabalhadores do patrimônio, imersos na mesma teia de relações sociais que buscavam descrever. Elaborava-se nova concepção de patrimônio que incluía o próprio trabalho dos profissionais da área como um bem disputado no mercado (e não só das ideias) digno de nota é a explicação que Irapoan Cavalcanti faz da contratação por projetos, ao tratar das relações de trabalho que a Fundação Pró-Memória deveria possuir. ${ }^{25}$ Ele pensava o patrimônio como um trabalho da sociedade, trabalho da memória, da construção e reconstrução das múltiplas identidades sociais e ainda da própria produção cultural, entendida como criação e recriação de suas condições de vida.

\section{O patrimônio como manifestação da diversidade cultural brasileira}

Por fim, o livro apresenta reiteradas defesas da necessidade do patrimônio de se aproximar e se relacionar de forma diferente com a sociedade. Essa intenção se manifestava nessa publicação e em outros textos do mesmo período, produzidos pela mesma instituição, como o número zero do Boletim Sphan/PróMemória, no qual encontramos seguinte afirmação, no tópico "O trabalho a ser desenvolvido", do último capítulo da publicação:

\footnotetext{
O espírito que deverá presidir ao trabalho à frente é o da inclusão ou reinserção na trajetória socioeconômica e cultural do país os monumentos, sítios e bens móveis, assim como dos núcleos urbanos e cidades que, por seu valor histórico, artístico, paisagístico, etnológico e arqueológico, integrem-se ao patrimônio histórico e artístico nacional. ${ }^{26}$
}

Dos quatro aspectos que o livro apresenta na conclusão - vistos ainda de forma preliminar, como o próprio texto afirma, por se tratar de obra programática - e que deveriam nortear as ações do órgão no futuro, um apenas era de continuidade em relação às ações passadas: "identificação, restauração, preservação e
25. "Nós vamos atuar através da elaboração de projetos. A cada coisa que demande fazer, nós definiremos um projeto. Então, averiguaríamos as necessidades de pessoal, material, serviços e, no momento em que terminar o projeto, esse conjunto de pessoal, material etc., será deslocado para outro projeto" (Iphan/1980, p. 138). Vide o último anexo dolivro, onde está transcrita e entrevista completa com Irapoanã Cavalcanti, cf. Instituto do Patrimônio Histórico e Artístico Nacional (1980).

26. Ibidem (p. 29). 
revitalização dos monumentos, sítios e bens móveis mencionados". Os três demais apontavam para a valorização e o reconhecimento da diversidade cultural brasileira:

- Inventário e documentação dos bens culturais - passados e presentes assim como dos bens culturais significativos quanto à dinâmica cultural brasileira; coleta, análise e referenciamento de dados relativos e seus processos de produção, circulação e consumo.

- Busca de explicitação das aspirações e características regionais, visando à efetiva integração das diversas comunidades brasileiras no interesse e no esforço para a preservação da identidade e do patrimônio cultural do país.

- Devolução ao público usuário - particularmente ao contexto sociocultural a que pertencem e de onde as originam - dos resultados dos trabalhos, pesquisas e registros realizados, através de museus, publicações, exposições etc., e também através do uso de novos meios de comunicação e interação com as comunidades.

A identificação de bens culturais ligados à "dinâmica cultural brasileira", a "explicitação das aspirações e características regionais, visando à efetiva integração das diversas comunidades brasileiras" e a "devolução ao público usuário" "dos resultados dos trabalhos, pesquisas e registros realizados" 27, por diversos meios, todas essas ações sinalizavam o esforço de inclusão das manifestações culturais populares no patrimônio.

Tarefa de inclusão ou reinserção, portanto, do patrimônio no destino nacional, em um trabalho que pressupunha reconhecer um isolamento anterior, a partir do momento em que se identificava um engessamento das concepções de patrimônio e cultura. Buscava-se ao mesmo tempo incorporar novas dimensões ao patrimônio, enquanto se acenava para uma tradição já consolidada, como se percebe no inesperado recurso à expressão "patrimônio histórico e artístico nacional" nessa citação. Um trabalho contraditório e complexo, pois fundia tradições distintas, formações díspares e práticas diversas, que nem todo artifício retórico era capaz de ocultar ou obscurecer: proteção e revitalização, memória e dinâmica cultural, monumento e documento, o passado e sua constante atualização. 
Nos balanços bibliográficos realizados sobre a década de 1980, a atuação de Antonio A. Arantes costuma ser destacada. Para citar apenas um exemplo, no texto intitulado "Quando o campo é o patrimônio", 28 Regina Abreu traça a história da criação do Grupo de Trabalho de Patrimônio, junto à diretoria da Associação Brasileira de Antropologia (ABA) e faz um levantamento das principais obras que propiciaram a criação desse campo. Nele, o livro Produzindo o passado é apresentado como obra pioneira nessa área de estudos, e Arantes é apontado como "o nome de maior destaque", "atuando duplamente como autoridade acadêmica e formulador de políticas". 29

Produzindo o passado foi organizado por Antonio Augusto Arantes e publicado pela editora Brasiliense em 1984. A publicação foi fruto de um seminário ocorrido entre jutho e agosto de 1983 e organizado pelo Condephaat, e nasceu da intenção do então novo presidente do órgão, o próprio Arantes, de trazer as discussões sobre cultura popular para dentro não apenas daquela instituição em particular, mas do campo do patrimônio cultural de maneira mais ampla, tal como o ele próprio destacou em entrevista à revista Ponto Urbe, revista do núcleo de antropologia urbana da USP. ${ }^{30}$

A importância dessa publicação - muito diversificada e desigual tanto na qualidade das contribuições quanto nos objetivos de cada texto - está no que trouxe como expressão de um olhar antropológico sobre o patrimônio e a cultura, com ênfase na popular. E pelo que representou na incorporação dos antropólogos, enquanto categoria profissional, nesse campo.

No mesmo movimento de aproximação dos grupos sociais que buscavam voz e reconhecimento no período da chamada redemocratização, que o Sphan/ Pró-Memória realizava desde 1979, o Condephaat nomeou como presidente o antropólogo Antonio Augusto Arantes, com a missão que o próprio assim descreveria, anos mais tarde:

No governo Montoro, no início do processo de redemocratização, fui convidado a presidir - Condephaat. Não havia no Condephaat espaço para levar essas questões adiante, mas eu era conhecido como o antropólogo que tinha feito aquele trabalho em São Miguel Paulista e tinha contestado alguns princípios já estabelecidos na preservação do patrimônio como assunto que apenas interessava às elites. $\bigcirc$ trabalho em São Miguel mostrava que a população é sensível, sim, às questões de patrimônio, ao ambiente em que vive, à qualidade desse ambiente e foi assim que sucedi o Prof. Aziz Ab'Saber, que tinha dado ênfase, em sua gestão, a questões ambientais. Coube a mim fortalecer os movimentos sociais associa-
28. Texto apresentado no seminário promovido pelo CPDOC e pelo Laboratório de Antropologia e História da UFRJ, "Quando o campo é o arquivo: etnografias, histórias e outras memórias guardadas", realizado em novembro de 2004 (Abreu, 2007).

29. Ibidem. p. 2.

30. Arantes; Torres (2008). 
31. Id. (2008, p. 10).

32. Ibid. (p. 10)

33. A mais completa análise histórica da trajetória do Condephaat ainda é a tese de doutorado de Marly Rodrigues, Alegorias do passado. A instituição do patrimônio no passado (1969-1987), defendida na Unicamp em 1994. Cf. Rodrigues (1994). dos à preservação e a integração da preservação à gestão urbana, através dos conselhos municipais de patrimônio. ${ }^{31}$

Como sintetizou o autor, seu esforço foi "por um lado, uma tentativa de diversificar as bases sociais da preservação, e, por outro, estabelecer canais de comunicação com as demais instituições de preservação municipais que surgiam" ${ }^{32}$

Tendo isso em vista, podemos compreender a publicação em questão, assim como o seminário que a originou, como expressão dos novos desafios que o campo se colocava naquele momento. Desafios esses que punham em evidência as disputas regionais pelo controle do discurso patrimonial, assim como os novos agentes sociais que emergiam no final da ditadura militar. O Condephaat buscava desenvolver, no estado de São Paulo, novas perspectivas em relação à cultura e ao patrimônio, colocando-se, assim, à frente das mudanças protagonizadas pelos agentes que atuavam nessa área naquele momento. Mudanças que tiveram na gestão de Arantes um momento de grande efervescência. ${ }^{33}$

Mesmo sem acesso à totalidade das contribuições do seminário, das palestras e debates então ocorridos, o que está disponível ao público é suficientemente ilustrativo não apenas de novos temas e preocupações que começavam a se impor ao tema do patrimônio, mas igualmente das ações que se propunham para enfrentar essa nova realidade.

A obra apresenta um prefácio, escrito pelo organizador do livro, seguido de três textos de comunicações ocorridas em uma mesa intitulada "Cultura, patrimônio e preservação", mais a transcrição do debate final. Os autores das comunicações - cada uma identificada apenas como "texto 1", "texto 2" e "texto 3" - foram, respectivamente, Willi Bolle, Eunice Ribeiro Durham e Waldisa Rússio. O debate, além dos três, e de Arantes, contou com a presença da arquiteta e urbanista Helena Saia. Em seguida, aparecem cinco artigos, oriundos de palestras ministradas no seminário: "Questões de identidade cultural", de Olympio Serra; "História e poder local", de Bela Feldman-Bianco; "Revitalização da capela de São Miguel Paulista", de Antonio Augusto Arantes; "A casa das retortas", de Paulo Mendes da Rocha; "Ouro Preto e Mariana", de Marco Aurélio Nunes Ferreira de Queiroz; e "O caso Pelourinho", de Paulo Ormindo de Azevedo.

Ao final do prefácio, o organizador anuncia a intenção de publicar um segundo volume com outras contribuições, mas isso jamais ocorreu. Por outro lado, aponta para a colaboração dos técnicos do Condephaat tanto na organização do seminário quanto na publicação do livro, assim como agradece à contribuição na compilação dos textos e "para a realização do seminário, as historiadoras Marly Rodrigues e Maria Auxiliadora Guzzo de Decca e a arquiteta Silvia Ferreira Santos Wolff" (p. 10). 
Um rápido olhar sobre as diferentes formações e áreas disciplinares dos convidados mostra a pluralidade das contribuições que forneceram, mas também os campos disciplinares que eram majoritariamente convocados a debater e intervir nas políticas públicas sobre o patrimônio cultural. Observa-se nítido predomínio de arquitetos e antropólogos nesses debates. ${ }^{34}$

Não trataremos a totalidade dessas contribuições - o livro por si só mereceria discussão mais ostensiva e aprofundada. A título de exemplo, o texto de Olympio Serra poderia ser facilmente articulado às discussões então crescentes no campo do patrimônio sobre os processos identitários indígenas e negros, sobretudo pela atuação do autor na Fundação Pró-Memória.

Queremos destacar apenas duas contribuições particularmente relevantes nessa obra: a comunicação apresentada pela professora Eunice Ribeiro Durham (texto II do livro) ${ }^{35}$ e as intervenções na mesa-redonda do próprio Arantes, além de seu (curto) prefácio. Ambas mereceriam investigação mais detida, mas é nesse segundo autor que nos deteremos para aprofundar um pouco algumas das questões mais importantes discutidas no seminário, fruto de debates intelectuais intensos naquele período e, como tentaremos mostrar, também incubadoras de abordagens e perspectivas fecundas para o futuro da preservação no Brasil. Em parte pelo papel que o autor assumiu como formulador e executor de uma política pública de patrimônio para o Estado de São Paulo, em parte pela natureza de suas contribuições, como destacaremos a seguir.

Tanto na apresentação que faz da obra quanto nas suas intervenções nos debates então realizados, Arantes traz como elementos para reflexão e às vezes, provocação, ideias que encerram novo olhar sobre o patrimônio, que resumiremos nos seguintes pontos:

\section{1) Cultura como produção e construção}

A ênfase na noção de que a cultura não é um resultado acabado de algo, uma história ou uma expressão artística, mas uma prática, que se processa no tempo; logo o passado também é produzido, e não somente como um constructo dos historiadores, mas também pela sociedade, que constante e interminavelmente - faz e refaz. Da mesma forma, então, a memória que o patrimônio elege e valoriza para preservar é uma construção social e política. Tal ideia é brevemente desenvolvida no prefácio, mas perpassa toda a publicação, como no próprio título da obra, traduzindo a centralidade que o autor nela enxerga. Se a cultura é um processo, uma construção constante, então possui temporalidades próprias, relativas aos grupos sociais que as detêm, cabendo ao Estado reconhecer e criar mecanismos de lidar com os diferentes tempos dessa cultura. ${ }^{36}$
34. Willie Bolle, professor de literatura, conhecido por seus estudo sobre Walter Benjamin; Eunice Durham, professora de antropologia e membro do Condephaat, Waldisa Rússio, museóloga, coordenadora do curso de museologia da Fundação Escola de Sociologia e Política; Olympio Serra, antropólogo da Fundação Pró- Memória ; Bela Feldman- Bianco, professora de antropologia da Unicamp; Paulo Mendes da Rocha, arquiteto e professor de arquitetura da Universidade de São Paulo (USP); Marco Aurélio Nunes Ferreira de Queiroz, arquiteto urbanista; e Paulo Ormindo de Azevedo, professor de arquitetura e urbanismo da Universidade Federal da Bahia (UFBA).

35. O texto de Eunice Durham propõe valiosa reflexão, ainda hoje relevante, sobre as relações entre cultura e patrimônio problematizando a questão da valoração e das concepções que embasam a formulação de políticas públicas.

36. Cf. Fonseca (2005) 
37. Arantes (1984, p. 81).

38. "o discurso não é simplesmente aquilo que traduz as lutas ou os sistemas de dominação, mas aquilo por que, pelo que se luta, o poder do qual nos queremos apoderar" (Foucault, 2007, p. 10).

39. Smith (2012, p. 11-12).

40. Arantes, op. cit., p. 80.

\section{2) Uma cultura específica de preservação}

Deve-se destacar a ideia de que "a cultura produzida por nós, intelectuais, técnicos, pesquisadores, políticos" ${ }^{\prime 37}$ e sua recepção (absorção, incorporação) pela sociedade é uma forma de cultura específica, uma cultura da preservação e que, portanto, assim deve ser vista e investigada. Essa é uma das afirmações, feita sem alarde, relevantes para um olhar crítico sobre o patrimônio cultural, especialmente para compreender a natureza do conhecimento especializado produzido sobre o patrimônio e seus contextos de produção. Sobretudo, enfatiza o impacto que esse conhecimento produz para a própria sociedade, sobre a qual ele se debruça. Por outro lado, aponta para a questão dos valores, nem sempre explícitos, que embasam a ação dos chamados especialistas, cujo conhecimento, portanto, participa da mesma cultura sobre a qual ele atua, pensa, descreve, interpreta.

Outra consequência dessa afirmação é que o discurso patrimonial pode ser visto como parte intrínseca e incontornável do processo de produção cultural: em outras palavras, ao ser proferido (por especialistas, agentes autorizados do patrimônio), esse discurso cria dupla camada de sentido, ${ }^{38}$ no qual, no ato de preservar, torna-se ele mesmo parte do processo de preservação, moldando as condições pelas quais o patrimônio pode ser visto, compreendido e valorado, criando suas próprias condições de sentido.

Uma melhor compreensão desses mecanismos de controle, exclusão, seleção e organização do discurso sobre o patrimônio, para usarmos o Foucault de A ordem do discurso, possibilita o conhecimento a respeito das "condições de funcionamento" e "acesso" desse discurso. Ou, como Laurajane Smith pontua ${ }^{39}$, as condições que autorizam algo a ser patrimônio ou alguém a pensá-lo e dizê-lo.

\section{3) Memória individual e coletiva no campo do patrimônio}

Por outro lado, o autor chama a atenção para uma diferença fundamental entre a preservação que a sociedade faz de si mesma l"a preservação da memória feita por nós mesmos") e "a preservação que se faz no sentido da constituição de algo que pretende ser patrimônio comum, extrapolando as histórias e as vidas individuais". 40 Não se trata aqui apenas da oposição entre o reconhecimento que a sociedade tem pelo que entende ser seu patrimônio e o reconhecimento que o Estado chancela como patrimônio nacional, mas uma outra oposição, mais discreta, entre a memória cultivada individualmente ou pelos grupos sociais, e a memória mais ampla de uma determinada sociedade, um "patrimônio comum" a diferentes indivíduos e grupos. Um patrimônio cuja constituição é mediatizada justamente pela cultura de preservação específica mencionada anteriormente, da ordem do conhecimento técnico especializado. 
A preservação da memória, a operação que funda e cria o patrimônio cultural, ao mesmo tempo se alimenta e transcende as identidades dos indivíduos e grupos sociais, mas, ao fazer isso, utiliza o que Paulo Peixoto chama de recurso metonímico dos processos de patrimonialização, ${ }^{41}$ obscurecendo as tensões, instabilidades e contradições que marcam os processos identitários. Essa é uma contribuição que não pode ser subestimada, uma vez que traz à superfície um dos mecanismos centrais da operação que produz o discurso patrimonial, pelo qual toma-se a parte pelo todo, podendo um único bem cultural representar uma identidade nacional. Operação embutida no jogo de linguagem que funda a narrativa patrimonial, e onde o processo de se construir identidades metonimicamente (do local ao nacional, e do nacional ao mundial), ${ }^{42}$ torna-se uma prática naturalizada e quase invisível.

Ao expor alguns dos fios, até então, em grande parte invisíveis, da trama que constitui o patrimônio, Arantes adotava um outro tipo de abordagem sobre o tema, que contribuiu significativamente para colocar em novos termos um modo de discutir e pensar o patrimônio cultural e sua preservação. Por esse ângulo, é necessário frisar que textos, como o que foi discutido, representaram tanto o aparecimento de novas concepções de patrimônio, quanto o adentrar de novas vozes que alteraram profundamente a configuração discursiva daquilo que se fala do/sobre o patrimônio.

\section{CONSIDERAÇÕES FINAIS}

Buscamos destacar algumas das inovações e transformações que o campo aqui em questão enfrentou entre o final da década de 1970 e o início da década de 1980. Em particular, analisamos duas obras estrategicamente produzidas por duas das mais importantes agências de proteção do patrimônio do país - o Sphan/ Pró-Memória e o Condephaat -, que sintetizaram o percurso dessas mudanças e, ao mesmo tempo, colocaram questões que trouxeram, mais do que novas concepções, novas formas de se pensar e falar sobre o tema, enfim, um novo discurso patrimonial, capazes de criar as condições de possibilidade do que intitulamos como uma abordagem historiográfica do patrimônio. ${ }^{43}$

De maneira alguma, isso significa que são as obras mais decisivas desse processo de transformação, nem que trouxeram as contribuições teóricas mais substanciais. A simples menção ao nome de Ulpiano Bezerra de Meneses e os artigos que publicou na década de 1980 bastam para demonstrar o contrário. ${ }^{44}$ Porém, acreditamos que o tipo de publicação a que nos dedicamos discutir nesse artigo faz uma conexão entre teoria e prática e coloca em plano diverso o
41. Peixoto (2004).

42. Vale ressaltar que essa configuração do discurso autorizado do patrimônio (Authorized Heritage Discourse - AHD, no original em inglês), que se utiliza desses processos metonímicos para afirmar certas identidades, atravessa diversas esferas de proteção do patrimônio: dos municípios até a Unesco responsável pela promoção do patrimônio mundial.

43. E que se desenvolveria, sobretudo a partir dos anos 1990 , com as publicações das obras de autores como José Reginaldo Gonçalves, Mariza Veloso Santos, Silvana Rubino, Cecília Londres e Márcia Chuva, entre outros. Sobre a constituição dessa abordagem historiográfica, cf. Chuva (2017).

44. "O objeto material como documento", por exemplo, texto de 1980, é uma das mais significativas contribuições teóricas sobre o patrimônio produzidas no período. Escrita do ponto de vista da arqueologia, possibilita discussões mais amplas sobre a natureza do patrimônio cultural. Cf. Meneses (1980). 
45. Smith, op. cit., p. 5, tradução nossa.

46. No caput do artigo 216 da Constituição de 1988, define-se o "patrimônio cultural brasileiro [como] os bens de natureza material e imaterial, tomados individualmente ou em conjunto, portadores de referência à identidade, à ação, à memória dos diferentes grupos formadores da sociedade brasileira" (Brasil, 2011). alcance de suas formulações, contribuindo para causar impacto significativo no cenário em que pretendia intervir.

O fato de ambas estarem relacionadas à ação de dois intelectuais da área de estudos da cultura popular - Aloísio Magalhães, em virtude de sua atuação anterior na criação e desenvolvimento do Centro Nacional de Referência Cultural (CNRC); Antonio Augusto Arantes, com trajetória mais vinculada ao mundo acadêmico, mas igualmente voltado à pesquisa de temas da cultura popular - não deve ser visto como casual, mas reflexo dos esforços dos órgãos públicos de se aproximarem e, quando possível, integrarem outras camadas sociais, para além daquelas tradicionalmente contempladas pelas políticas dedicadas à cultura no país.

Dessa forma, pode-se compreender essas obras como contribuições fundamentais para o reordenamento do chamado discurso autorizado de patrimônio, no sentido de que o "patrimônio também pode ser entendido como um discurso preocupado com a negociação e regulação de significados e práticas sociais associados à criação e recriação de 'identidades'". 45

Da mesma maneira que se discutiam as identidades do que viria a ser chamado posteriormente, no texto constitucional, de "grupos formadores da nação", ${ }^{46}$ ou melhor, dos processos identitários que constituíam os diversos grupos sociais que se distribuíam nas diferentes regiões do país, colocava-se em questão, de modo ainda incipiente, o próprio papel que os formuladores das políticas e práticas governamentais de patrimônio, os especialistas, os agentes do patrimônio, possuíam na elaboração de um discurso patrimonial.

Discurso que, ao ser enunciado, constituía, por sua vez, sua própria identidade social e profissional, como trabalhadores do patrimônio, detentores de sua própria cultura de preservação, parte da mesma teia de relações em que habitavam as culturas populares, as edificações civis e religiosas, os vestígios arqueológicos, as obras de arte, todas as manifestações, enfim, que compunham a "civilização brasileira". 


\section{REFERENCIAS}

FONTES IMPRESSAS

ARANTES, Antonio Augusto (org.). Produzindo o passado. São Paulo: Brasiliense, 1984.

INSTITUTO DO PATRIMÔNIO HISTÓRICO E ARTÍSTICO NACIONAL. Boletim SPHAN/PróMemória. 1979-1990.

INSTITUTO DO PATRIMÔNIO HISTÓRICO E ARTÍSTICO NACIONAL. Proteção e revitalização do patrimônio bistórico e artístico no Brasil: uma trajetória. Brasília, DF: Fundação Nacional Pró-Memória, 1980.

LIVROS, ARTIGOS E TESES

ABREU, Regina. Quando o campo é o patrimônio: notas sobre a participação de antropólogos nas questões do patrimônio. Sociedade e Cultura, Goiânia, v. 8, 2007, p. 37-52.

BRASIL. Constituição da República Federativa do Brasil. Brasília, DF: Senado Federal, 2011.

CALABRE, L. "Políticas Culturais no governo militar: O Conselho Federal de Cultura". XIII Encontro de História Anpuh - Rio - Identidades, 2008. Disponível em: <http://www. encontro2008.rj.anpuh.org/resources/content/anais/1212692933_ARQUIVO_Anpuh2008.pdf>, acesso em 10/11/2020.

CHUVA, Marcia. Os arquitetos da memória: sociogênese das práticas de preservação do patrimônio cultural no Brasil. RJ: UFRJ, 2009.

CHUVA, Márcia. Por uma história da noção de patrimônio cultural no Brasil. Revista do Patrimônio, Brasília, DF, n. 34, 2012b, p. 147-165.

CHUVA, Márcia. Possíveis narrativas sobre duas décadas de patrimônio: de 1982 a 2002. Revista do Patrimônio, Brasília, DF, n. 35, 2017, p. 79-103. 
DUTRA, Maria Vitória de Moraes. Centro Nacional de Referência Cultural: o desconhecido acervo consagrado. 2017. Dissertação (Mestrado em Preservação do Patrimônio Cultural) Instituto do Patrimônio Histórico e Artístico Nacional, Rio de Janeiro, 2017.

FONSECA, Maria Cecília Londres. O Patrimônio em processo: trajetória da política federal de preservação no Brasil. Rio de Janeiro: IPHAN, 2005.

FONSECA, Maria Cecília Londres. Referências Culturais: base para novas políticas de patrimônio. In: INSTITUTO DO PATRIMÔNIO HISTÓRICO E ARTÍSTICO NACIONAL. Inventário nacional de referências culturais: manual de aplicação. Brasília, DF: IPHAN, 2000.

FOUCAULT, Michel. A ordem do discurso. São Paulo: Loyola, 2007.

GONÇALVES, José Reginaldo Santos. A retórica da perda: os discursos do patrimônio cultural no Brasil. Rio de Janeiro: Editora UFRJ, 2002 (1996).

GUEDES, Maria Tarcila Ferreira; MAIO, Luciana Mourão. Bem cultural. In: GRIECO, Bettina; TEIXEIRA, Luciano; THOMPSON, Analucia (orgs.). Dicionário IPHAN de Patrimônio Cultural. 2. ed. Brasília, DF: IPHAN, 2016.

Ver LEAL, Cláudia (org.). Consultores da Unesco no Brasil: Michel Parent. Rio de Janeiro: IPHAN, 2009.

LEAL, Cláudia F. Baeta. et al. História e civilização material na Revista do Patrimônio. Revista do Patrimônio, Brasília, DF n. 34, 2012, p. 167-197.

MAGALHÃES, Aloísio. E Triunfo? A questão dos bens culturais no Brasil. Rio de Janeiro. Nova Fronteira; Fundação Roberto Marinho, 1985.

MENESES, Ulpiano Toledo Bezerra de. O objeto material como documento. São Paulo: CONDEPHAAT, 1980.

MENESES, Ulpiano Toledo Bezerra de. O campo do Patrimônio Cultural: uma revisão de premissas. In: INSTITUTO DO PATRIMÔNIO HISTÓRICO E ARTÍSTICO NACIONAL. Fórum Nacional do Patrimônio Cultural: Sistema Nacional de Patrimônio Cultural: desafios, estratégias e experiências para uma nova gestão, 2009, Ouro Preto. Anais [...]. Brasília, DF: IPHAN, 2012. p. 25-39.

MENESES, Ulpiano Bezerra de. Revista do Patrimônio, Brasília, DF, n. 36, 2017, p. 39-51. 
MOTTA, Lia (org.). Um panorama do campo da preservação do patrimônio cultural. (Texto Analucia Thompson). Rio de Janeiro: IPHAN, 2015.

NASCIMENTO, Flavia Brito do. Patrimônio cultural e escrita da história: a hipótese do documento na prática do IPHAN nos anos 1980. Anais do Museu Paulista: História e Cultura Material, São Paulo, v. 24, n. 3, 2016, p. 121-147.

PEIXOTO, Paulo. A identidade como recurso metonímico dos processos de patrimonialização. Revista Crítica de Ciências Sociais, Coimbra, v. 70, 2004, p. 183-204.

RODRIGUES, Marly. Alegorias do passado: a instituição do patrimônio no passado (1969-1987). 1994. Tese (Doutorado em História), Universidade Estadual de Campinas, Campinas, 1994.

RUBINO, Silvana. Um mapa do Brasil passado. Revista do Patrimônio, Brasília, DF, n. 24, p. 97-105, 1996.

SANTOS, Mariza Veloso Motta. Nasce a Academia SPHAN. Revista do Patrimônio, Brasília, DF, n. 24, p. 77-95, 1996.

SILVA, Cíntia Mayumi de Carli. Revista do Patrimônio: editor, autores e temas. 2010. Dissertação (Mestrado em História, Política e Bens Culturais). Fundação Getulio Vargas, Rio de Janeiro, 2010. Disponível em: <https://bit.ly/38chF2g>. Acesso em: 10 jul. 2018.

SMITH, Laurajane. Uses of heritage. New York: Routledge, 2006.

\section{ENTREVISTAS}

ARANTES, Antonio Augusto; TORRES, Lilian de Lucca. Entrevista: Antônio Augusto Arantes. Ponto Urbe, São Paulo, v. 3, 2008. Disponível em: <https://bit.ly/366YJzp>. Acesso em: 19 abr. 2019.

Artigo apresentado em: 20/1/2020. Aprovado em 10/9/2020.

\section{(cc) BY}

All the contents of this journal, except where otherwise noted, is licensed under a Creative Commons Attribution Licens 